\title{
Design, Microwave-Assisted Synthesis and Biological Activities of 1,2,4-Triazol-3-Yl-Thiazolidin-4-Ones
}

Monia Aouali ${ }^{\star *}$, Fatma Masmoudi ${ }^{3}$, Fatma Allouche ${ }^{1}$, Laurent El Kaim², Fakher Chabchoub ${ }^{1}$ and Mohamed Trigui $^{\mathbf{3}}$

${ }^{1}$ Laboratoire de Chimie Appliquée: Hétérocycles, Corps Gras et Polymères, Faculté des Sciences, University of Sfax, Tunisie

${ }^{2}$ Laboratoire Chimie et Procédés, DCSO, UMR 7652, Ecole Nationale Supérieure de Techniques Avancées, 828 Bd des Maréchaux, France

${ }^{3}$ Laboratoire des Biopesticides, Centre de biotechnologie de Sfax Université de Sfax, Tunisie

\begin{abstract}
A new 3-(5-alkyl-2-phenyl-2H-1,2,4-triazol-3-yl)thiazolidin-4-ones derivatives were obtained by condensation of 5-amino-1,2,4-triazoles, mercaptoacetic acid with aromatic aldehydes and catalyzed by $\mathrm{Sm}\left(\mathrm{SO}_{3} \mathrm{CF}_{3}\right)_{3}$ using microwave irradiation. The prepared compounds were tested for their antioxidant, antibacterial and antifungal proprieties. Some of these compounds displayed significant activities. Among them, compound $2 \mathbf{e}$ exhibited remarkable activity against a broad spectrum of Gram positive, negative bacteria and pathogenic fungal strains with low MIC values. The investigation of the mode of action of the most potent antifungal compounds on the fungus Pythium phanidermatum showed a membrane alteration and distortions of hyphal morphology. The newly synthesized compounds exhibited also promising radical scavenging activity.
\end{abstract}

Keywords: Aminotriazoles; Triazolothiazolidinones; Antimicrobial activity; Antioxidant activity

\section{Introduction}

Bacterial infections are a common problem in hospitals and clinical setting worldwide and have become an increasing public health problem. The indiscriminate and the overuse of antibiotics has led to the emergence of antibiotic-resistant bacteria such us Methicillinresistant Staphylococcus aureus [1]. Thus, designing and developing new antimicrobial agents having new modes of action are being a big challenge for scientific. Triazolothiazolidinones have received intensive research interests due to their biological activities, and found a wide range of applications in pharmaceutical and agrochemical field. Thiazolidin-4-one is a versatile scaffold for designing potential bioactive agents. In fact, some derivatives of thiazolidin-4-one showed an antioxidant, anticancer [2], antitumor [3], anti-inflammatory [4], antimicrobial [5], anti-HIV [6], antiviral [7], anticonvulsant [8] and antihypertensive [9] activities. Moreover, Reactive Oxygen Species (ROS) are various forms of activated oxygen. A disproportion of the reactive oxygen species and the absence of their scavenge systems in cells leads to oxidative stress and increases the risk of several human chronic diseases [10]

In previous papers $[11,12]$ we reported that derivatives of aminotriazoles can be used such as starting materiel for obtaining polyheterocyclic compounds having interest biological activities. In continuation, we present here our study of three-component reaction of aminotriazoles, aromatic aldehydes and mercaptoacetic acid and valorization of biological activities of some triazolothiazolidinones obtained.

\section{Materials and Methods}

\section{Chemistry}

All microwave-assisted reactions were carried out in synthetic microwave: Monowave 300 with a maximum power of $300 \mathrm{~W}$. The reactions were followed by TLC (aluminium sheets with silica gel 60 F254 from Merck). ${ }^{1} \mathrm{H}$ NMR and ${ }^{13} \mathrm{C}$ NMR spectra were recorded at 400 $\mathrm{MHz}$ using $\mathrm{CDCl}_{3}-\mathrm{d}_{6}$ on a Bruker Spectrometer and High Resolution Mass Spectra HRMS. Chemical shifts $(\delta)$ are expressed in parts per million (ppm) relative to tetramethylsilane (TMS) as internal reference. The multiplicities abbreviations were used: s, singlet; d, doublet; dd doublet of doublet; $t$, triplet; $q$, quadruplet; $m$, multiplet. Coupling constants $J$ are expressed in Hertz. Melting points were measured on an Electrothermal apparatus.
General procedure for the synthesis of 3-(5-alkyl-2-phenyl-2H1,2,4-triazol-3-yl)thiazolidin-4-ones 2a-p: 5-amino-1-phenyl-1,2,4triazoles $(1 \mathrm{mmol})$ and aromatics aldehydes $(1 \mathrm{mmol})$ were added to a $10 \% \mathrm{Sm}\left(\mathrm{SO}_{3} \mathrm{CF}_{3}\right)_{3}$ in $1 \mathrm{~mL}$ dry toluene, The mixture were stirred at $180^{\circ} \mathrm{C}$ in sealed tube by irradiating microwave for $15 \mathrm{~min}$. Subsequently, thioglycolic acid $(1.3 \mathrm{mmol})$ was added and was irradiated in a microwave at $140^{\circ} \mathrm{C}$ for $15 \mathrm{~min}$. After, $N, N^{\prime}$-dicyclohexylcarbodiimide DCC $(1.3 \mathrm{mmol})$ and additional dry toluene were added. The mixture was stirred at $140^{\circ} \mathrm{C}$ in sealed tube by irradiating microwave for $15 \mathrm{~min}$ reaction.

Then, after cooled to room temperature, 1,3-dicyclohexylurea (DCU) was removed by filtration and the residue was purified by chromatography on silica gel (petroleum ether/ $\mathrm{CH}_{2} \mathrm{Cl}_{2}(6: 4)$ ).

\section{Biological activities}

Microorganisms and growth conditions: The synthesized compounds were tested against a panel of microorganisms including eight bacteria and six fungal strains obtained from American Type Culture Collection (ATCC), local culture Collection of Tunisian Microorganisms "CTM" of the Centre of Biotechnology of Sfax, Collection of the Institut Pasteur(CIP) and Plant PathologyExperimental Institute (ISPAVE). The tested pathogenic bacteria are: Bacillus cereus ATCC 14579, Staphylococcus aureus ATCC 25923, Enterococcus faecalis ATCC 29212, Micrococcus luteus ATCC 1880, Esherichia coli ATCC 25922, Klebsiella pneumoniae ATCC 10031, Salmonella enteritidis (food isolate 824), Listeria monocytogenes (food isolate 2132). The fungi tested are Rhizopus nigricans (LPAP26); Alternaria alternata CTM 10230; Pythium phanidermatum (LPAP32); Fusarium culmorum ISPAVE 21W; Fusarium graminearum ISPAVE 271; Aspergillus flavus (food isolate). Bacteria were cultivated in Muller-Hinton agar ( $\mathrm{MH}$ )

*Corresponding author: Monia Aouali, Laboratoire de Chimie Appliquée: Hétérocycles, Corps Gras et Polymères, Faculté des Sciences, University of Sfax, 3018 Sfax, Tunisie, Tel: +21626299719; E-mail: aoualimonia@yahoo.fr

Received April 11, 2016; Accepted April 21, 2016; Published April 26, 2016

Citation: Aouali M, Masmoudi F, Allouche F, Kaim LE, Chabchoub F, et al. (2016) Design, Microwave-Assisted Synthesis and Biological Activities of 1,2,4-Triazol-3YI-Thiazolidin-4-Ones. Med chem (Los Angeles) 6: 264-269. doi:10.4172/21610444.1000356

Copyright: (C) 2016 Aouali M, et al. This is an open-access article distributed under the terms of the Creative Commons Attribution License, which permits unrestricted use, distribution, and reproduction in any medium, provided the original author and source are credited. 
(Oxoid Ltd, UK) at $37^{\circ} \mathrm{C}$ and on Potato Dextrose Agar (PDA) medium at $28^{\circ} \mathrm{C}$ for fungal strains. These strains were sub-cultured on a fresh appropriate agar plate $24 \mathrm{~h}$ prior to any antimicrobial test. Therefore, a freshly bacterial inoculum of $10^{7} \mathrm{cfu} / \mathrm{mland}$ a spore suspension of $10^{6}$ spores $/ \mathrm{ml}$ (measured by Malassez blade) were prepared the day of the experiments.

Antimicrobial assays: Antibacterial and antifungal assays were performed by agar well diffusion method as described by Trigui [13] and broth micro dilution assay in sterile 96-well micro plate saccording to Eloff [14]. For agar well diffusion assay, the surface of agar plates were streaked by a freshly cell suspension adjusted to $10^{7} \mathrm{CFU} / \mathrm{mL}$ for bacterial strains and $10^{5}$ spores $/ \mathrm{mL}$ for fungi. Then, wells $(6 \mathrm{~cm})$ were punched into the inoculated agar and compounds were added to each well. DMSO (20\%), used to dissolve the compounds, was used as negative controls. Gentamicin (10 $\mu \mathrm{g} /$ wells) and Amphotericin B (20 $\mu \mathrm{g} /$ well) were used as positive control for bacterial and fungal strains respectively. After diffusion of the compounds at $4^{\circ} \mathrm{C}$ for $2 \mathrm{~h}$, plates were incubated at $37^{\circ} \mathrm{C}$ for $24 \mathrm{~h}$ for bacterial strains and $72 \mathrm{~h}$ for fungi at $28^{\circ} \mathrm{C}$. The activity was evaluated by measuring the zones of inhibition around the well. All tests were repeated three times.

The broth micro dilution method aimed to determine the Minimum inhibitory concentrations (MICs) of each compounds by a twofold serial dilution. The range of compounds concentration tested in the micro plate is from $0.01-5.5 \mathrm{mg} / \mathrm{mL}$. After dilution, $10 \mu \mathrm{L}$ of cell suspension was added to each test well. The plates were then covered and incubated at the appropriate temperature for the microorganisms under investigation. Gentamicin and Amphotericin B were used as positive drug controls against bacterial and fungal strains. The MIC was defined as the lowest concentration of the compound that inhibits the visible growth of a microorganism after incubation. The $p$-iodonitrotetrazolium chloride $(25 \mu \mathrm{L}$ of INT) was used as an indicator of microorganism growth.

Antioxidant activity: Radical scavenging activity of synthesized compounds was determined using DPPH as a reagent according to the method of Kirby and Schmidt [15] with slight modifications. Compounds were diluted in methanol to a final concentration of 0.5 $\mathrm{mg} / \mathrm{ml}$ and then $500 \mu \mathrm{L}$ were added to $1 \mathrm{~mL}$ of DPPH radical solution in methanol $4 \%(\mathrm{w} / \mathrm{v})$. The mixture was vigorously shaken and incubated in the dark at room temperature for $30 \mathrm{~min}$. The absorbance was measured at $517 \mathrm{~nm}$ against a blank and activity was compared to the ascorbic acid used as positive control. The percent DPPH scavenging activity was calculated using the following equation: DPPH scavenging effect $(\%)=$ A control - A sample $/$ A control $) \times 100$

A control is the absorbance of the control reaction containing all reagents except the tested compound. A sample is the absorbance of the tested compound. All tests were repeated three times.

\section{Results and Discussion}

\section{Chemistry}

The synthetic strategy adopted to obtain the target compounds is presented in Scheme 1.5-amino-1,2,4-triazoles 1a-creacts with aromatic aldehydes catalyzed by samarium (III) trifluoromethanesulfonic $\mathrm{Sm}\left(\mathrm{SO}_{3} \mathrm{CF}_{3}\right)_{3}$ in toluene under microwave irradiation followed by addition of excess of mercaptoacetic acid. After that, we added dicyclohexylcarbodiimide (DCC). The dicyclohexylurea (DCU), which was precipitated, was removed by filtration.

According with experimental protocol we supposed initially the formation of imine due to the action of aminotriazoles with aromatic aldehydes. In the second step, the nucleophilic sulfur atom of the mercaptoacetic acid, attack iminic carbon, then intramolecular cyclization followed by elimination of water molecule affords the thiazolidin-4-one 2a-p.

The dehydrating agent DCC accelerates the intramolecular cyclization process and increases the yield of the reaction as well. The obtained products were isolated by conventional workup in satisfactory yields (Table 1).

The spectral data and HRMS of the new compounds reported in this study correlate with the proposed structures. The ${ }^{1} \mathrm{H}$ NMR spectra of compounds $\mathrm{C}_{5}-\mathrm{H}$ signals were observed at $\delta 3.65-3.9$ as double doublets due to chiral center at $\mathrm{C}_{2}$.

The developed synthetic protocol was used to access a series of triazol-3yl-thiazolidinones $\mathbf{2 a - p}$, which were obtained in moderate yields ranging from $45 \%$ to $56 \%$.

\section{Biological activities}

Antibacterial: The in vitro antibacterial activity of compounds (2b$\mathbf{h}, \mathbf{2 n}$ and $\mathbf{2 p}$ ) were carried out against a panel of five Gram-positive and three Gram-negative bacteria and compared to the gentamicin used as standard antibiotic. The results of antibacterial testing, using well diffusion method and broth micro dilution technique, are presented in Table 2 . Out of the nine newly synthesized compounds, the compound 2e exhibited the strongest antibacterial activity with inhibition zone ranged from 11 to $23 \mathrm{~mm}$ and very low minimum inhibitory concentration (MIC) values. It was also noticed that the Gram-positive bacteria Bacillus cereus and Staphylococcus aureus are the most sensitive bacteria to the all synthetized compounds whereas Gram negative ones are resistant to these compounds except for 2e. Gram-negative bacteria are generally less susceptible to antibiotics than the Gram-positive bacteria, since they have an outer membrane which plays the role of a barrier to the biomolecules [16].

Antifungal: The synthesized compounds were also evaluated for their in vitro antifungal activity against various phytopathogenic<smiles>[Y8]C=Nc1nc([R])nn1-c1ccccc1CCCCCC</smiles>

Scheme 1: Synthesis of 3-(5-alkyl-2-phenyl-2H-1,2,4-triazol-3-yl)thiazolidin-4-ones. Reagents and conditions: (i) $\left.\mathrm{Sm}_{\left(\mathrm{SO}_{3}\right.} \mathrm{CF}_{3}\right)_{3}(10 \% \mathrm{~mol})$, toluene, $\mathrm{MW}, 180^{\circ} \mathrm{C}, 15 \mathrm{~min}$. (ii) $\mathrm{SHCH}_{2} \mathrm{COOH}, \mathrm{MW}, 140^{\circ} \mathrm{C}, 15 \mathrm{~min}$. (iii) $\mathrm{DCC}, \mathrm{MW}$, toluene, $140^{\circ} \mathrm{C}, 15 \mathrm{~min}$. 


\begin{tabular}{|c|c|c|c|}
\hline Compounds & $\mathbf{R}_{1}$ & $\mathrm{Ar}$ & Yields (\%) \\
\hline$\underline{2 a}$ & $\mathrm{CH}_{3}$ & & 45 \\
\hline$\underline{2 b}$ & $\mathrm{CH}_{3}$ & & 40 \\
\hline$\underline{2 c}$ & $\mathrm{CH}_{3}$ & & 47 \\
\hline$\underline{2 d}$ & $\mathrm{CH}_{3}$ & & 52 \\
\hline$\underline{2 \mathrm{e}}$ & $\mathrm{CH}_{3}$ & & 55 \\
\hline$\underline{2 f}$ & $\mathrm{CH}_{3}$ & & 55 \\
\hline$\underline{2 g}$ & $\mathrm{C}_{2} \mathrm{H}_{5}$ & & 50 \\
\hline$\underline{2 h}$ & $\mathrm{C}_{2} \mathrm{H}_{5}$ & & 48 \\
\hline$\underline{2 i}$ & $\mathrm{C}_{2} \mathrm{H}_{5}$ & & 47 \\
\hline$\underline{2 i}$ & $\mathrm{C}_{2} \mathrm{H}_{5}$ & & 52 \\
\hline$\underline{2 k}$ & $\mathrm{C}_{2} \mathrm{H}_{5}$ & & 45 \\
\hline$\underline{21}$ & $\mathrm{C}_{2} \mathrm{H}_{5}$ & & 55 \\
\hline$\underline{2 m}$ & $\mathrm{C}_{2} \mathrm{H}_{5}$ & & 56 \\
\hline$\underline{2 n}$ & $\mathrm{C}_{2} \mathrm{H}_{5}$ & & 55 \\
\hline$\underline{20}$ & $\mathrm{C}_{6} \mathrm{H}_{5} \mathrm{CH}_{2}$ & & 54 \\
\hline$\underline{2 p}$ & $\mathrm{C}_{6} \mathrm{H}_{5} \mathrm{CH}_{2}$ & & 48 \\
\hline
\end{tabular}

Table 1: Yields of new 3-(5-alkyl-2-phenyl-2H-1,2,4-triazol-3-yl)thiazolidin-4-ones.

fungus using the agar well diffusion method and the minimal inhibitory concentrations (MIC, $\mathrm{mg} / \mathrm{ml}$ ) by the two fold broth dilution technique in liquid plate count agar (PDA). The results, presented in Table 3, showed that all the synthetized 3-(5-alkyl-2phenyl-2H-1,2,4-triazol-3-yl)thiazolidin-4-ones derivatives exhibits broad-spectrum antifungal activity towards several phytopathogenic fungi. Compound $2 \mathrm{e}$ showed the greatest antifungal activity against all tested fungi with low MIC values ranging from 0.172 to $1.375 \mathrm{mg} /$ $\mathrm{ml}$. To a lesser extent, compounds $\mathbf{2 c}$ and $\mathbf{2 h}$ were active against $83 \%$ of the tested fungi with MIC values higher than $2 \mathbf{e}$. Compounds $2 \mathbf{p}$ followed by $\mathbf{2} \mathbf{b}$ were inactive. The other compound showed a moderate antifungal activity. 


\begin{tabular}{|c|c|c|c|c|c|c|c|c|c|c|}
\hline \multirow[b]{3}{*}{ Compounds } & \multirow[b]{3}{*}{ Activity } & \multicolumn{8}{|c|}{ Bacterial strains } & \multirow[t]{3}{*}{ Activity $(\%)$} \\
\hline & & \multicolumn{5}{|c|}{ Gram positive bacteria } & \multicolumn{3}{|c|}{ Gram negative bacteria } & \\
\hline & & $B C$ & Sa & $E f$ & MI & $L m$ & $E c$ & $\mathrm{Se}$ & $K p$ & \\
\hline \multirow{2}{*}{$2 b$} & $I^{(a)}$ & 16 & 10 & 0 & 0 & 0 & 0 & 0 & 0 & \multirow{2}{*}{25} \\
\hline & $\mathrm{MIC}^{(b)}$ & $>5.5$ & - & - & - & - & - & - & - & \\
\hline \multirow[b]{2}{*}{ 2c } & $\mathrm{IZ}$ & 23 & 12 & 0 & 0 & 0 & 0 & 0 & 0 & \multirow[b]{2}{*}{25} \\
\hline & MIC & 2.75 & - & - & - & - & - & - & - & \\
\hline \multirow[b]{2}{*}{$2 d$} & $\mathrm{IZ}$ & 15 & 12 & 0 & 0 & 0 & 0 & 0 & 0 & \multirow{2}{*}{25} \\
\hline & MIC & 2.75 & - & - & - & - & - & - & - & \\
\hline \multirow[b]{2}{*}{$2 e$} & $\mathrm{IZ}$ & 23 & 17 & 12 & 13 & 21 & 11 & 11 & 12 & \multirow[b]{2}{*}{100} \\
\hline & MIC & 0.021 & 0.021 & 0.687 & 0.172 & 0.687 & 2.75 & 2.75 & 1.375 & \\
\hline \multirow[b]{2}{*}{$2 f$} & IZ & 20 & 13 & 0 & 0 & 20 & 0 & 0 & 0 & \multirow[b]{2}{*}{37.5} \\
\hline & MIC & 0.172 & 0.172 & - & - & 0.344 & - & - & - & \\
\hline \multirow[b]{2}{*}{$2 \mathrm{~g}$} & $\mathrm{IZ}$ & 16 & 10 & 0 & 0 & 0 & 0 & 0 & 0 & \multirow[b]{2}{*}{25} \\
\hline & MIC & 0.172 & 5.5 & - & - & - & - & - & - & \\
\hline \multirow[b]{2}{*}{$2 \mathrm{~h}$} & IZ & 18 & 10 & 0 & 0 & 0 & 0 & 0 & 0 & \multirow[b]{2}{*}{25} \\
\hline & MIC & 1.375 & $>5.5$ & - & - & - & - & - & - & \\
\hline \multirow[b]{2}{*}{$2 n$} & $\mathrm{IZ}$ & 20 & 0 & 0 & 0 & 0 & 0 & 0 & 0 & \multirow[b]{2}{*}{12.5} \\
\hline & MIC & 0.687 & - & - & - & - & - & - & - & \\
\hline \multirow[b]{2}{*}{$2 p$} & $\mathrm{IZ}$ & 17 & 0 & 0 & 0 & 0 & 0 & 0 & 0 & \multirow[b]{2}{*}{12.5} \\
\hline & MIC & 0.172 & - & - & - & - & - & - & - & \\
\hline \multirow[b]{2}{*}{ Gentamicin $^{(c)}$} & IZ & 20 & 20 & 20 & 18 & 20 & 25 & 25 & 22 & \multirow[b]{2}{*}{100} \\
\hline & MIC & 0.004 & 0.004 & 0.004 & 0.004 & 0.001 & 0.002 & 0.002 & 0.002 & \\
\hline DMSO $20 \%$ & IZ & 0 & 0 & 0 & 0 & 0 & 0 & 0 & 0 & \\
\hline
\end{tabular}

Bacterial strains: Bc: Bacillus cereus ATCC14579; Sa: Staphylococcus aureus ATCC25923; Ef: Enterococcus faecalis ATCC 29212; MI: Micrococcus luteus ATCC 1880; Lm: Listeria monocytogenes (FI 2132); Ec: Escherichia Coli ATCC 25922; Se: Salmonella enteritidis (food isolate); Kp: Klebsiella pneumonia CIP 32147. (a) Diameter of inhibition zones including diameter of well $6 \mathrm{~mm}$. (b) MIC: The Minimum Inhibitory Concentrations in mg/mL. (c) Gentam: Gentamicin was used as a standard antibiotic at a concentration of $15 \mu \mathrm{g} /$ Well. (-) Inactive.

Table 2: The antibacterial activity in vitro of the target compounds.

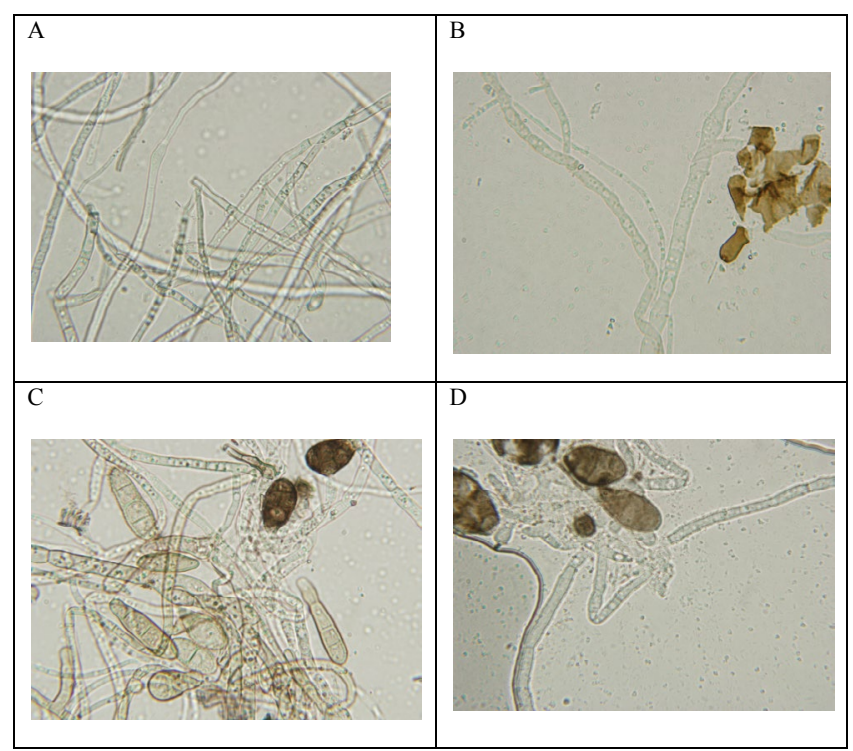

Figure 1: Light microphotograph of mycelium growing of Pythium phanidermatum (LPAP32) on PDB with or without compounds $\underline{\mathbf{2 e}}, \underline{\mathbf{2 c}}$ and $\underline{\mathbf{2 g}}$. A: Control mycelium of Pythium phanidermatum; B and C: Mycelium collected from cultures supplemented with $687 \mu \mathrm{g} / \mathrm{ml}$ of $\underline{\mathbf{2 e}}$ and $\underline{2 \mathrm{c}}$; D: Mycelium collected from cultures supplemented with $2.75 \mu \mathrm{g} / \mathrm{ml}$ of $\underline{\mathbf{2 g}}$.

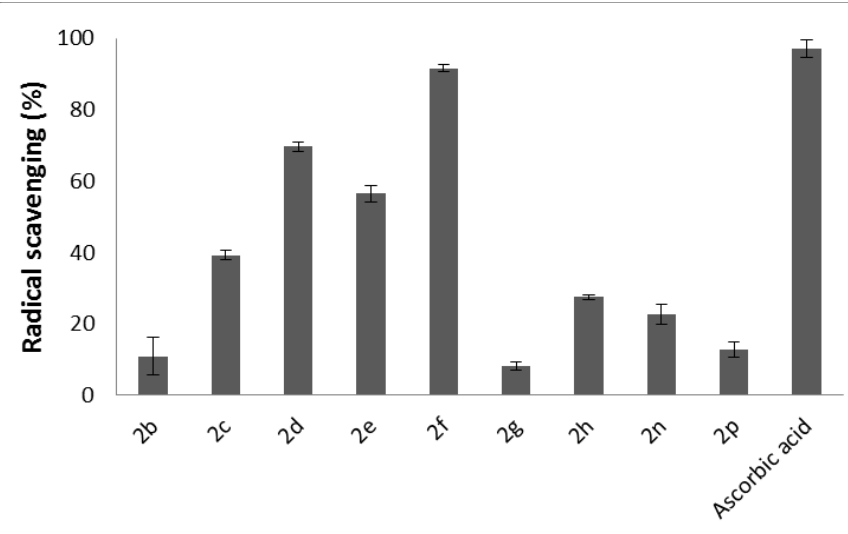

Figure 2: Free radical scavenging activity.

Understanding the mechanism of action of antifungal compounds is desirable. To the antifungal investigate activity of compounds 2e, $2 \mathrm{c}$ and $2 \mathrm{~g}$ in liquid medium and their mode of action, Pythium phanidermatum was used as positive control. This fungal strain is a cosmopolitan pathogen with a wide host range causing damping off, root and stem rots, and blights of grasses and fruit. It is of economic concern on most annuals, cucurbits, and grasses. It is considered one of the water molds because it survives and grows best in wet soils. Pythium 


\begin{tabular}{|c|c|c|c|c|c|c|c|c|}
\hline \multirow[b]{2}{*}{ compounds } & \multirow[b]{2}{*}{ Activity } & \multicolumn{6}{|c|}{ Fungal strains } & \multirow[t]{2}{*}{ Activity(\%) } \\
\hline & & $R n$ & $A a$ & $P p$ & $F c$ & $\mathrm{Fg}$ & Af & \\
\hline \multirow[b]{2}{*}{$2 b$} & IZ & 11 & 0 & 0 & 0 & 0 & 0 & \multirow{2}{*}{16.66} \\
\hline & MIC & 2.75 & - & - & - & - & - & \\
\hline \multirow[b]{2}{*}{ 2c } & $\mathrm{IZ}$ & 10 & 17 & 17 & 13 & 0 & 10 & \multirow[b]{2}{*}{83.33} \\
\hline & MIC & 1.375 & 2.75 & 0.687 & 0.343 & - & 5.5 & \\
\hline \multirow[b]{2}{*}{$2 d$} & $\mathrm{IZ}$ & 12 & 0 & 13 & 09 & 0 & 08 & \multirow[b]{2}{*}{66.66} \\
\hline & MIC & 0.687 & - & 0.687 & 1.375 & - & 5.5 & \\
\hline \multirow[b]{2}{*}{$2 e$} & IZ & 14 & 14 & 14 & 15 & 15 & 12 & \multirow[b]{2}{*}{100} \\
\hline & MIC & 0.172 & 0.172 & 0.687 & 0.172 & 1.375 & 1.375 & \\
\hline \multirow[b]{2}{*}{$2 f$} & $\mathrm{IZ}$ & 0 & 0 & 15 & 10 & 0 & 10 & \multirow[b]{2}{*}{50} \\
\hline & MIC & - & - & 1.375 & 2.75 & - & 2.75 & \\
\hline \multirow[b]{2}{*}{$2 \mathrm{~g}$} & $\mathrm{IZ}$ & 11 & 0 & 20 & 12 & 0 & 08 & \multirow[b]{2}{*}{66.66} \\
\hline & MIC & 0.687 & - & 2.75 & 2.75 & 2.75 & 2.75 & \\
\hline \multirow[b]{2}{*}{$2 \mathrm{~h}$} & $\mathrm{IZ}$ & 10 & 14 & 17 & 17 & 16 & 0 & \multirow[b]{2}{*}{83.33} \\
\hline & MIC & 5.5 & 5.5 & 2.75 & 2.75 & 2.75 & - & \\
\hline \multirow[b]{2}{*}{$2 n$} & $\mathrm{IZ}$ & 11 & 0 & 16 & 0 & 0 & 12 & \multirow[b]{2}{*}{50} \\
\hline & MIC & 0.876 & - & 1.375 & - & - & 2.75 & \\
\hline \multirow[b]{2}{*}{$2 p$} & $\mathrm{IZ}$ & 0 & 0 & 0 & 0 & 0 & 0 & \multirow[b]{2}{*}{0} \\
\hline & MIC & - & - & - & - & - & - & \\
\hline \multirow[b]{2}{*}{ Amphotericin ${ }^{(4)}$} & $\mathrm{IZ}$ & 10 & 12 & 18 & 14 & 14 & 10 & \multirow[b]{2}{*}{100} \\
\hline & MIC & 0.343 & 0.172 & 0.312 & 0.085 & 0.343 & - & \\
\hline DMSO $20 \%$ & $\mathrm{IZ}$ & 0 & 0 & 0 & 0 & 0 & 0 & - \\
\hline
\end{tabular}

Fungal strains: Rn: Rhizopus nigricans LPAP26; Aa: Alternaria alternata CTM 10230; Pp: Pythium phanidermatum LPAP32; Fc: Fusarium culmorum ISPAVE 21W; Fg: Fusarium graminearum ISPAVE 271; Af: Aspergillus flavus (food isolate). (1) Diameter of inhibition zones of compounds including the diameter of the well (6 mm), (2) Minimal Inhibition Concentration (MIC) in mg/ml, (3) Amphotericine B was used as antifungal standard at $20 \mu \mathrm{g} / \mathrm{mL}$, (4) -: activity not detected.

Table 3: The antifungal activity in vitro of the target compounds.

phanidermatum were cultured for $48 \mathrm{~h}$ in a Potato Dextrose Broth (PDB) medium supplemented with $687 \mu \mathrm{g} / \mathrm{ml}$ of $2 \mathbf{e}, 2 \mathrm{c}$ and $2750 \mu \mathrm{g} / \mathrm{ml}$ of $\mathbf{2 b}$. The monitoring of the antifungal activity showed a general degradation of mycelium compared to the control. Microscopic examination of the control mycelium (untreated cell) showed regular cell structure with free and linearly shaped hyphae, and clearly visible homogenous cytoplasm. However, the treated mycelium with the compounds 2 e (1 CMI) and 2c (1 CMI) showed morphological changes. The hyphae became distorted with swelling along its structure and budded apical tips. Therefore, the alterations included loss of cytoplasm content, pigmentation due to the permeability to the product $2 \mathbf{e}$ and $2 \mathbf{c}$ and distortions of hyphal development (Figure 1B and C). The mycelia cultivated in the medium added with $2 \mathbf{g}$ appeared to present also morphological changes with swelling along the hyphae (Figure 1D). The effect is more pronounced with compounds $2 \mathrm{e}$ followed by $2 \mathrm{c}$ than with $2 \mathrm{~g}$. It was reported previously that the mode of action of antifungal compound could be attributed to an inhibition of metabolic activity leading to a disorder on enzymatic reactions, fungal morphogenesis and growth [17].

\section{Antioxidant activity}

The scavenging of the stable DPPH radical model is a widely used method to evaluate antioxidant activity. The principle of the assay is based on the color change of the DPPH solution from purple to yellow as the radical is quenched by the antioxidant. The color changes can be measured quantitatively by spectrophotometer absorbance at $517 \mathrm{~nm}$. Ascorbic acid was used as antioxidant reference substance. The tested compounds showed variable antioxidant activity at a final concentration of $0.5 \mathrm{mg} / \mathrm{ml}$. Among the nine tested compounds, the most potent radical scavenger effect was obtained with $2 \mathbf{f}$ which showed an inhibition of $91.57 \%$ compared to $98 \%$ using ascorbic acid. The compounds $\mathbf{2 d}$ followed by $\mathbf{2 e s h o w e d ~ a l s o ~ a n ~ a n t i o x i d a n t ~ a c t i v i t y ~}$ with respectively 69.62 and $56.41 \%$ of inhibition (Figure 2). A lower activity was obtained in the case of $\mathbf{2 g}, \mathbf{2 b}$ and $\mathbf{2 p}$.

\section{Conclusion}

In conclusion, this paper presented an improved microwaveassisted combining with the use of DCC for synthesizing 3-(5-alkyl2-phenyl-2H-1,2,4-triazol-3-yl)thiazolidin-4-ones in moderates yields. The research subscribed in this paper indicates a wide spectrum of biological activities exhibited by 1,2,4-triazol-3-yl-thiazolidin-4one derivatives. The biological profiles of these new generations of compounds would represent a fruitful matrix for further development of better antifungal, antibacterial and antioxidant agents.

\section{References}

1. Bassetti M, Righi E (2016) Safety profiles of old and new antimicrobials for the treatment of MRSA infections. Expert Opin Drug Saf 15: 467-481.

2. Joseph A, Shah CS, Kumar SS, Alex AT, Maliyakkal N, et al. (2013) Synthesis in vitro anticancer and antioxidant activity of thiadiazole substituted thiazolidin4-ones. Acta Pharm 63: 397-408.

3. Grasso S, Chimirri A, Monforte P, Fenech G, Zappalà M, et al. (1988) Compounds with potential antitumor activity. VI--2-Alkyl-3-[2-(1,3,4thiadiazolyl)]-4-thiazolidinones. Farmaco Sci 43: 851-856.

4. Geronikaki AA, Lagunin AA, Hadjipavlou-Litina DI, Eleftheriou PT, Filimonov DA, et al. (2008) Computer-aided discovery of anti-inflammatory thiazo- 
Citation: Aouali M, Masmoudi F, Allouche F, Kaim LE, Chabchoub F, et al. (2016) Design, Microwave-Assisted Synthesis and Biological Activities of 1,2,4-Triazol-3-YI-Thiazolidin-4-Ones. Med chem (Los Angeles) 6: 264-269. doi:10.4172/2161-0444.1000356

lidinones with dual cyclooxygenase/lipoxygenase inhibition. J Med Chem 51: 1601-1609.

5. Gaur VB, Shah VH, Parikh AR (1990) Studies on 4-thiazolidinones. Preparation and antimicrobial Activity of 2-aryl-3-(5-o-hydroxyphenyl/p-nitrophenyl-1,3,4thiadiazol-2-yl)-5-carboxymethyl-4-thiazolidinones. Acta Cienc Indica Chem 16C: $437-444$

6. Chen H, Bai J, Jiao L, Guo Z, Yin Q, et al. (2009) Design, microwave-assisted synthesis and HIV-RT inhibitory activity of 2-(2,6-dihalophenyl)-3-(4,6-dimethyl5-(un)substituted-pyrimidin-2-yl)thiazolidin-4-ones. Bioorg Med Chem 17: 3980-3986.

7. Rawal RK, Katti SB, Kaushik-Basu N, Arora P, Pan Z (2008) Non-nucleoside inhibitors of the hepatitis $C$ virus NS5B RNA-dependant RNA polymerase: 2-aryl-3-heteroaryl-1,3-thiazolidin-4-one derivatives. Bioorg Med Chem Lett 18: 6110-6114.

8. Chimirri A, Grasso S, Monforte AM, Zappala M, De Sarro A, et al. (1991) Synthesis and anticonvulsant properties of 3-(1,3,4-thiadiazol-2-yl) thiazolidin4-ones. Farmaco 46: 935-943.

9. Bhandari SV, Bothara KG, Patil AA, Chitre TS, Sarkate AP, et al. (2009)Design, synthesis and pharmacological screening of novel antihypertensive agents using hybrid approach. Bioorg Med Chem 17: 390-400.

10. Rani V, Deep G, Singh RK, Palle K, Yadav UC (2016) Oxidative stress and metabolic disorders: Pathogenesis and therapeutic strategies. Life Sci 148 : 183-193.
11. Aouali M, Allouche F, Zouari I, Mhalla D, Trigui M, et al. (2014) Synthesis, Antibacterial, and Antifungal Activities of Imidazo[2,1-c][1,2,4]triazoles and 1,2,4-triazolo[4,3-a]pyrimidinones. Synthetic Commu 44: 748-756.

12. Aouali M, Mhalla D, Allouche F, ElKaim L, Tounsi S, et al. (2015) Synthesis antimicrobial and antioxidant activities of imidazotriazoles and new multicomponent reaction toward 5-amino-1-phenyl[1,2,4]triazole derivatives. Med ChemRes 24: 2732- 2741

13. Trigui M, Hsouna AB, Tounsi S, Jaoua S (2013) Chemical composition and evaluation of antioxidant and antimicrobial activities of Tunisian Thymelaeahirsuta with special reference to its mode of action. Ind Crop Prod 41: 150-157.

14. Eloff JN (1998) A sensitive and quick microplate method to determine the minimal inhibitory concentration of plant extracts for bacteria. Planta Med 64: 711-713.

15. Kirby AJ, Schmidt RJ (1997) The antioxidant activity of Chinese herbs for eczema and of placebo herbs I. J Ethnopharmacol 56: 103-108.

16. Chopra I (2003) The increasing use of silver-based products as antimicrobial agents: a useful development or a cause for concern?. J Antimicrob Chemoth 59: $587-590$

17. Odds FC, Brown AJ, Gow NA (2003) Antifungal agents: mechanisms of action Trends Microbiol 11: 272-279. 